University of South Carolina

Scholar Commons

$3-31-2011$

\title{
Electrospinning Fabrication, Structural and Mechanical Characterization of Rod-Like Virus-Based Composite Nanofibers
}

\author{
Laying Wu \\ University of South Carolina - Columbia \\ Jianfeng Zang \\ University of South Carolina - Columbia \\ L. Andrew Lee \\ University of South Carolina - Columbia \\ Zhongwei Niu \\ University of South Carolina - Columbia, niu.z@mail.chem.sc.edu \\ Gary C. Horvatha \\ University of South Carolina - Columbia
}

See next page for additional authors

Follow this and additional works at: https://scholarcommons.sc.edu/chem_facpub

Part of the Materials Chemistry Commons, and the Virology Commons

\begin{abstract}
Publication Info
Published in Journal of Materials Chemistry, Volume 21, Issue 24, 2011, pages 8550-8557.

(c) Journal of Materials Chemistry 2011, Royal Society of Chemistry.
\end{abstract}

This Article is brought to you by the Chemistry and Biochemistry, Department of at Scholar Commons. It has been accepted for inclusion in Faculty Publications by an authorized administrator of Scholar Commons. For more information, please contact digres@mailbox.sc.edu. 


\section{Author(s)}

Laying Wu, Jianfeng Zang, L. Andrew Lee, Zhongwei Niu, Gary C. Horvatha, Vaughn Braxtona, Arief C. Wibowo, Michael A. Bruckman, Soumitra Ghoshroy, Hans-Conrad zur Loye, Xiaodong Li, and Qian Wang 


\section{Journal of \\ Materials \\ Chemistry}




\title{
Materials Chemistry
}

Cite this: J. Mater. Chem., 2011, 21, 8550

www.rsc.org/materials

PAPER

\section{Electrospinning fabrication, structural and mechanical characterization of rod-like virus-based composite nanofibers $\dagger$}

\author{
Laying Wu, ${ }^{a b}$ Jianfeng Zang, ${ }^{c}$ L. Andrew Lee, ${ }^{a}$ Zhongwei Niu, ${ }^{d}$ Gary C. Horvatha, ${ }^{a}$ Vaughn Braxtona, ${ }^{a}$ \\ Arief Cahyo Wibowo, ${ }^{a}$ Michael A. Bruckman, ${ }^{a}$ Soumitra Ghoshroy, ${ }^{b}$ Hans-Conrad zur Loye, ${ }^{a}$ Xiaodong Li ${ }^{* c}$ \\ and Qian Wang*a
}

\author{
Received 6th January 2011, Accepted 25th February 2011 \\ DOI: $10.1039 / \mathrm{c} 1 \mathrm{jm} 00078 \mathrm{k}$
}

Tobacco mosaic virus (TMV) was electrospun with polyvinyl alcohol (PVA) into continuous TMV-PVA composite nanofibers to form a biodegradable nonwoven fibrous mat as an extracellular matrix (ECM) mimetic. Morphological characterizations by electron microscopy showed that the addition of varying amounts of TMV resulted in homogeneous nanofibers without phase separation and did not change the diameter of the composite nanofibers. The orientation of TMV in as-spun fibers could be readily controlled and post-processing of the nonwoven TMV-PVA mat significantly improved its water resistance. In addition, tensile tests were performed on individual nanofibers, which revealed that the TMV-PVA composite nanofibers achieved a comparable Young's modulus as PVA nanofibers. Since the modification of TMV is readily achieved via genetic or chemical methods, this process offers a facile way to incorporate a variety of functionalities into polymer nanofibers. As a demonstration of its potential as ECM mimetic, a mutant TMV containing RGD peptide was co-spun with PVA and the resulting fibrous substrates were used to promote cell growth.

\section{Introduction}

Electrospinning has been widely used to fabricate fibers with diameters ranging from sub-micrometre down to nanometre for various biomedical applications such as tissue engineering and drug delivery., An as-spun fiber network generated by electrospinning forms loosely connected three-dimensional mats exhibiting interconnected pores with a large surface-to-volume ratio, which can resemble the extracellular matrix (ECM) structure and support cell growth. ${ }^{3,4}$ Polyvinyl alcohol (PVA) is an FDA-approved, biocompatible and biodegradable polymer. ${ }^{5}$ The intrinsic properties of PVA, such as hydrophilicity, good chemical and thermal stabilities, and semi-crystalline molecular structure, enable us to process it into hydrogel, films and nanofibers for biomedical applications including contact lenses,

${ }^{a}$ Department of Chemistry and Biochemistry \& Nanocenter, University of South Carolina, Columbia, SC, 29208, USA. E-mail:wang@mail.chem. sc.edu; Fax: +1 803-777 9521; Tel: +1 803-7778436

${ }^{b}$ Department of Biological Sciences and the Electron Microscopy Center, University of South Carolina, Columbia, SC, 29208, USA

'Department of Mechanical Engineering, University of South Carolina, Columbia, SC, 29208, USA. E-mail: lixiao@engr.sc.edu; Fax: +1 803777 0106; Tel: +1 803-7778011

${ }^{d}$ Institute of Physics and Chemistry, Chinese Academy of Sciences, Beijing, 100190, P.R. China

$\dagger$ Electronic supplementary information (ESI) available: Details of the EDC coupling reaction and MALDI MS data. See DOI: 10.1039/c1jm00078k artificial organs and drug delivery systems. ${ }^{6,7}$ Efforts have also been made to mimic the unique structures and specific functions of natural ECM by co-electrospinning PVA with proteins providing new materials and scaffolds. ${ }^{8,9}$

Co-electrospinning of polymers and nanoparticles has been applied to improve cell-scaffold interactions to guide cell fate. ${ }^{10}$ Viruses are highly organized three-dimensional (3D) nanostructures ranging widely in shape from spheres, rods to filaments and in size from tens to hundreds of nanometres. The genetic programmability and site-specific chemistry at the nearatomic scale provide unprecedented opportunities for the fabrication of nanomaterials with novel functionalities. ${ }^{11-14}$ Recently, viruses have drawn tremendous attention and been studied as reaction vessels ${ }^{15,16}$ and nanotemplates for materials development. ${ }^{17,18}$ In previous studies, tobacco mosaic virus (TMV), turnip yellow mosaic virus (TYMV), cowpea mosaic virus (CPMV), and bacteriophage M13 have been extensively utilized in modulating cell uptake and cell adhesion, spreading, proliferation and differentiation. ${ }^{19-23}$

Although many papers have been published in the synthesis of polymer-virus composites, ${ }^{24-27}$ only a few studies have been reported to produce uniform composite fibers by co-electrospinning of polymers with viral particles. ${ }^{28-30}$ In this paper, we report, for the first time to our knowledge, the fabrication of nanostructured TMV-PVA fibrous mats with different compositions through the electrospinning process. The orientation of viruses in nanofibers was investigated as the TMV concentration 
varied. The water resistant properties of the as-spun fibers were measured to determine the stability. Because the mechanical properties of the fibrous scaffold used for tissue engineering can greatly affect cell morphology, proliferation and differentiation, ${ }^{31}$ we here present a new approach for in situ nanomechanical measurement of the quantitative stress-strain properties of individual nanofibers using a nanomanipulator placed within a scanning electron microscope (SEM). In addition, we demonstrated that a variety of functionalities can be introduced into the fibrous materials using this process. For instance, the mutant TMV with inserted GRGDSPG sequence was co-spun with PVA into nanofibers, which could be used as substrates for cell adhesion studies. These findings are significant and can find more application in fabricating bioactive fibrous materials.

\section{Materials and methods}

\subsection{Materials}

Polyvinyl alcohol (PVA) $\left(M_{\mathrm{w}} \approx 60 \mathrm{kDa}, 98 \%\right.$ hydrolyzed) was purchased from Fluka. Propargylamine (PPA) and hydroxybenzotriazole (HOBt) were purchased from Sigma-Aldrich. 1-Ethyl-3-(3-dimethylaminopropyl)carbodiimide (EDC) was purchased from Thermo Fisher Scientific. Deionized (DI) water was produced from a Millipore Purification System $(18 \mathrm{M} \Omega \cdot \mathrm{cm}$ at $25^{\circ} \mathrm{C}$ ).

\subsection{TMV purification}

Wild type TMV was harvested from TMV virus infected leaves. In brief, TMV was extracted from infected leaves by adding $10 \mathrm{mM}$ potassium phosphate buffer ( $\mathrm{pH} 7.8$ ) with $0.2 \% \beta$-mercaptoethanol and centrifuged at $9000 \mathrm{rpm}$ for $15 \mathrm{~min}$. The supernatant was clarified with an equal volume of $\mathrm{CHCl}_{3}$ and $n$ butanol (1: 1 ratio). Toward the aqueous supernatant, 10\% PEG 8000 and $0.2 \mathrm{M} \mathrm{NaCl}$ were added to precipitate TMV. After the centrifugation, the pellets were resuspended in $10 \mathrm{mM}$ phosphate buffer. Finally, the pure TMV viruses were obtained after the process of the ultracentrifugation for $2.5 \mathrm{~h}$ at $42000 \mathrm{rpm}$.

\subsection{Generation of mutant TMV}

The TMV coat protein was mutated using overlap-extension PCR. ${ }^{32}$ The plasmid template for PCR was prepared by removing the NcoI and KpnI fragment from the TMV U3/12-4 plasmid (a gift from Richard Nelson). ${ }^{33}$ This fragment contains the entire TMV coat protein gene. The fragment was inserted into the cloning vector pBluescript $\mathrm{SK}(+)$ II. This plasmid was designated pCP-NK. Two complementary mutagenic oligos were made containing the 'GRGDSPG' sequence. The forward primer (F) was (5'-TCTGGTCCTGCAACTGGAAGAGGAGACTCT $C C A G G A$ TGAGGTAGTCAAGAT- $\left.3^{\prime}\right)$ and the reverse primer (R) was (5'-ATCTTGACTACCTCA TCCTGGAGAGTCTCCT CTTCCAGTTGCAGGACCAGA-3'). The inserted sequence was italicized. Two PCR reactions were performed in parallel. The M13F primer was paired with the mutagenic primer $F$ while the M13R primer was paired with the mutagenic primer $R$. The products of the two PCR reactions were gel purified and combined in a third reaction using the M13F and M13R primers.
This PCR product was digested with NcoI and KpnI and cloned into the TMV U3/12-4 plasmid now designated TMV-RGD. The mutated coat protein was confirmed by sequencing. The TMV-RGD plasmid was cut at the unique KpnI site. Synthetic RNA was then synthesized using the MEGAscript T7 kit (Ambion) following the manufacturer's instructions. Ten micrograms of RNA per tobacco leaf was used for inoculation.

\subsection{MALDI-TOF MS analysis}

Viruses were denatured by adding guanidine hydrochloride $(6 \mathrm{~mL}, 6 \mathrm{M})$ to the sample $(24 \mathrm{~mL})$ and mixing for $10 \mathrm{~min}$ at room temperature. Denatured proteins were spotted on MTP 384 target plate using Millipore ZipTip $\mu$-C18 tips to remove excess salts. MALDI-MS analysis was performed using a Bruker Ultra-Flex I TOF/TOF mass spectrometer.

\subsection{Coelectrospinning TMV-PVA nanofibers}

In a typical experiment, TMV solution (in deionized water) was added to a pre-chilled $12 \mathrm{wt} \%$ PVA aqueous solution with gentle stirring to obtain virus concentrations ranging from 0.17 to $1.7 \mathrm{mg} \mathrm{mL}^{-1}$. Nanofibers were fabricated by the electrospinning process in a humidity-controlled chamber under a high voltage of $12 \mathrm{kV}$ and a feeding rate of $3.5 \mu \mathrm{L} \mathrm{min}{ }^{-1}$. The ground collection plate of aluminium foil was located at a fixed distance of $10 \mathrm{~cm}$ from the needle tip. The nanofibers were collected on the grounded target.

\subsection{Cell culture and characterization}

Baby hamster kidney (BHK) cells were purchased from ATCC (CRL-10314) and passaged four times before using in cell adhesion experiments. Cells were seeded on coelectrospun PVA and TMV fibrous substrates in a 12-well plate (Corning) at a cell density of $5 \times 10^{4}$ cells $\mathrm{mL}^{-1}$. Cell adhesion to fibrous substrates was monitored under serum free conditions in high glucose Dulbecco's modified eagle's medium (DMEM) (HyClone) supplemented with $4 \mathrm{mM}$ L-glutamine, $1 \%$ penicillin and streptomycin (HyClone) after $1 \mathrm{~h}$ and $12 \mathrm{~h}$ via optical microscopy. All the studies were done in triplicate.

Immunostaining. To observe cell adhesion and their actin filaments, cells were fixed after $1 \mathrm{~h}$ and $12 \mathrm{~h}$ of the cell seeding. Cells were washed three times with PBS and then fixed with $4 \%$ paraformaldehyde for $30 \mathrm{~min}$ at room temperature and washed thrice in PBS. Each sample was permeabilized for $15 \mathrm{~min}$ in $1 \times$ PBS with $0.1 \%$ Triton X-100 and blocked in 3\% bovine serum albumin (BSA, Sigma-Aldrich)/PBS for $30 \mathrm{~min}$ at room temperature. Afterward, $5 \mu \mathrm{L}$ of rhodamine-phalloidin (stock solution $14 \mu \mathrm{M}$ ) were added to each well. After cells were incubated for $20 \mathrm{~min}$ on a rocker, $5 \mu \mathrm{L}$ of DAPI (stock solution $0.5 \mathrm{mg} \mathrm{mL}^{-1}$ ) was added to each well and incubated for $10 \mathrm{~min}$ at room temperature. Then the samples were washed with $1 \times$ PBS and $0.05 \%$ Tween 20. Finally, the samples were mounted on microscope slides and viewed under an Olympus IX81 fluorescence microscope.

Scanning electron microscopy. Cells were washed three times in PBS and fixed with cacodylate-buffered $2.5 \%$ glutaraldehyde for 
$2 \mathrm{~h}$ at room temperature. After washing three times with $0.1 \mathrm{M}$ cacodylate buffer ( $\mathrm{pH}$ 7.2), cells were post-fixed with $1 \% \mathrm{OsO}_{4}$ buffered with $0.1 \mathrm{M}$ cacodylate for $60 \mathrm{~min}$ at $4{ }^{\circ} \mathrm{C}$ and washed three times with $0.1 \mathrm{M}$ cacodylate buffer. The cells were then dehydrated in a series of ethanol washes $(30 \%, 50 \%, 70 \%, 80 \%$, $95 \%$, and $2 \times 100 \%$ ) for $10 \mathrm{~min}$ each. In order to avoid the distortions caused by changing surface tension, the specimens were processed though critical point drying apparatus (Ladd Research Industries, Inc.). A thin layer of gold $(\sim 20 \mathrm{~nm})$ was sputter coated on the samples, after which the samples were viewed with a Zeiss UltraPlus FESEM.

\section{Results and discussion}

\subsection{Nanofibers of PVA with TMV particles}

TMV-PVA nanofibers were fabricated by co-electrospinning the mixture solution of TMV and PVA. Under the above described conditions, both PVA and TMV-PVA nanofibers were successfully fabricated with diameters between $200 \mathrm{~nm}$ and $400 \mathrm{~nm}$, and were randomly arranged in a nonwoven network as viewed by SEM (FEI Quanta ESEM 200) in Fig. 1. In comparison to the asspun PVA fibers, the addition of TMV virus does not introduce any phase separation. The fabricated nanofibers remain uniform without beads and appear random distributions, forming nonwoven mats as seen in Fig. 1b-f. With the increase of TMV concentration from 0.17 to $1.7 \mathrm{mg} \mathrm{mL}^{-1}$, the electrospun fibers retained the homogeneous distribution on the collector and displayed a slight change in diameters.

\subsection{TMV orientation in as-spun nanofibers}

Fig. 2a shows a structural model of TMV and Fig. $2 b$ is a typical TEM image of TMV solution. To localize the TMV distribution and the orientation, TMV-PVA nanofibers at a concentration of $0.7 \mathrm{mg} \mathrm{mL}^{-1}$ were analyzed using TEM. The majority of TMV particles form well-aligned orientation along the long axis of the fiber, which is pointed out by white arrows (Fig. 2c and d). As TMV concentration increases to $5.0 \mathrm{mg} \mathrm{mL}^{-1}$, although the virus remains homogeneously distributed in the hybrid fiber, the orientation of TMV in nanofibers has changed, as shown in

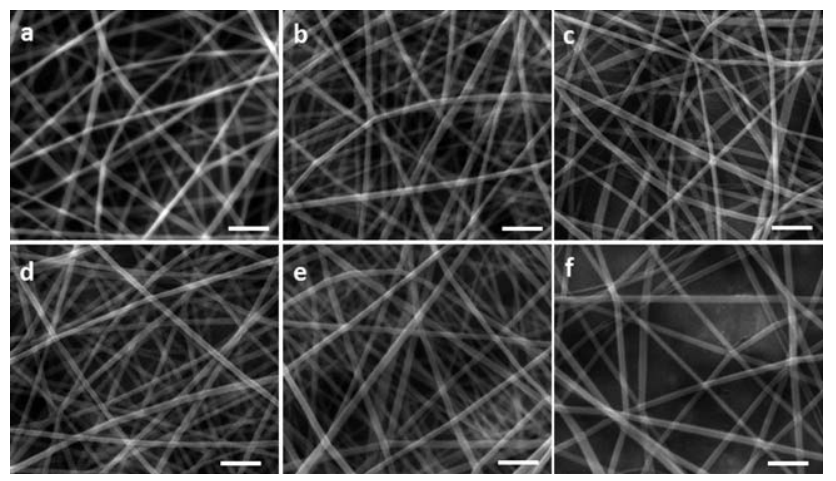

Fig. 1 SEM images show as-spun TMV-PVA nanofibers at $12 \mathrm{wt} \%$ PVA and TMV concentrations of (a) $0.0 \mathrm{mg} \mathrm{mL}^{-1}$, (b) $0.17 \mathrm{mg} \mathrm{mL}^{-1}$, (c) $0.34 \mathrm{mg} \mathrm{mL}^{-1}$, (d) $0.68 \mathrm{mg} \mathrm{mL}^{-1}$, (e) $1.20 \mathrm{mg} \mathrm{mL}^{-1}$, and (f) $1.70 \mathrm{mg} \mathrm{mL}^{-1}$. Scale bars are $2 \mu \mathrm{m}$.
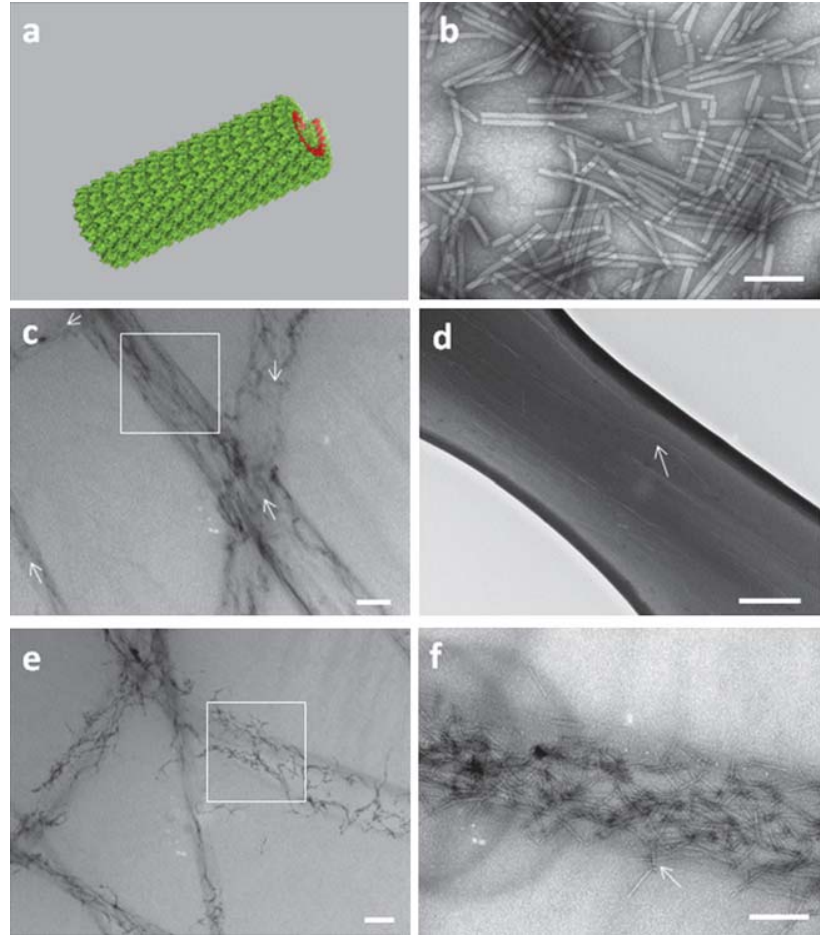

Fig. 2 (a) PyMol rendering of TMV with coordinates from PDB Protein Databank. (b) Rod-like structure of isolated wild type TMV viruses under TEM. (c) TEM image showing the orientation and distribution of TMV particles (arrowed) aligned in TMV-PVA fibers at a TMV concentration of $0.7 \mathrm{mg} \mathrm{mL}^{-1}$. (d) A high magnification TEM image shows the orientation of TMV in nanofibers from the squared area of (c). (e) The orientation and the distribution of TMV in as-spun nanofibers at a TMV concentration of $5.0 \mathrm{mg} \mathrm{mL} \mathrm{mL}^{-1}$. (f) A high magnification TEM image from the magnified squared area of (e). Scale bars are $200 \mathrm{~nm}$.

Fig. 2e. Virus particles are positioned randomly and some TMV particles protrude out of the surface (Fig. 2f).

\subsection{Improvement of water resistance of TMV-PVA fibers}

For tissue engineering and drug delivery applications, we need to improve the water resistance of the TMV-PVA composite fibers. When the as-spun TMV-PVA nanofiber mat was immersed in water, the fibers instantaneously dispersed in water due to the good solubility of PVA. It has been reported that PVA can be chemically cross-linked with a variety of substances including glutaraldehyde and maleic anhydride or physically crystallized by the action of chemical agents such as methano $1^{34}$ and ethano ${ }^{35}$ or alternatively by the freeze-thaw technique. ${ }^{36}$ In our study, TMV-PVA electrospun fibers were treated with physical techniques: (1) TMV-PVA mats were soaked in methanol or ethanol for $24 \mathrm{~h}$, respectively, and then dried in a vacuum oven overnight at room temperature or (2) TMV-PVA mat was strengthened with a freeze-thaw treatment for three cycles. In each cycle the sample was put in $-80{ }^{\circ} \mathrm{C}$ refrigerator for $2 \mathrm{~h}$ then thawed at room temperature for another $2 \mathrm{~h}$. The diffraction pattern of the electrospun fibers before and after treatment was checked by $\mathrm{X}$-ray diffraction (XRD) (Rigaku Ultima IV Powder X-ray diffraction system, using $\mathrm{Cu} \mathrm{K} \alpha$ radiation, $\lambda=1.5418 \AA$ ). The XRD pattern of untreated TMV-PVA fibers is featureless as 


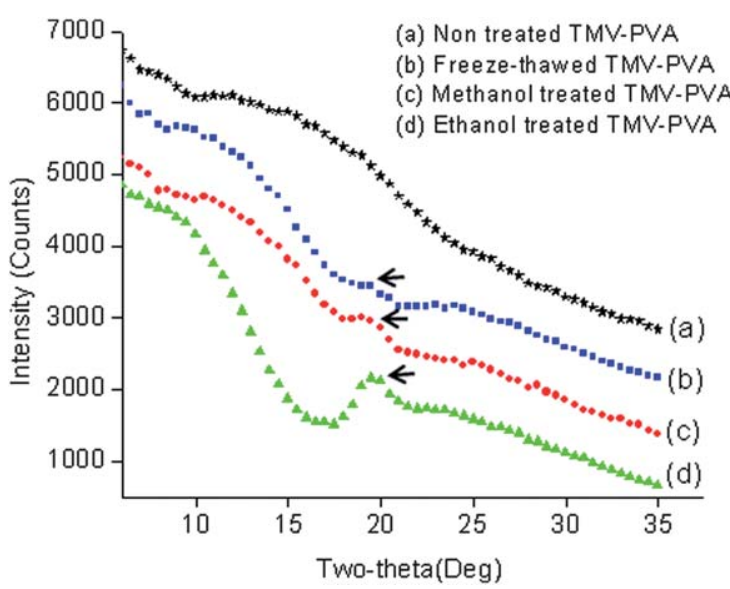

Fig. 3 XRD diffraction patterns of TMV-PVA electrospun fibers: (a) untreated, (b) freeze-thaw treated, (c) methanol treated, and (d) ethanol treated. The arrows point to the newly induced peaks. TMV concentrations are $0.34 \mathrm{mg} \mathrm{mL}^{-1}$ in all the cases.

shown in Fig. 3a, indicating an amorphous structure of PVA. However, after TMV-PVA fibers were soaked in methanol or ethanol or came from a freeze-thaw treatment, a narrow peak appeared at about $2 \theta=20^{\circ}$ (Fig. 3b-d), which meant that the treatment led to a long-range ordering of PVA within the TMVPVA composite fibers. In addition, ethanol treated TMV-PVA nanofibers (Fig. 3d) presented a more significant diffraction peak than the sample treated with methanol (Fig. 3b).

The improved stability of TMV-PVA in water was further evaluated by field emission SEM (Zeiss UltraPlus FESEM) and
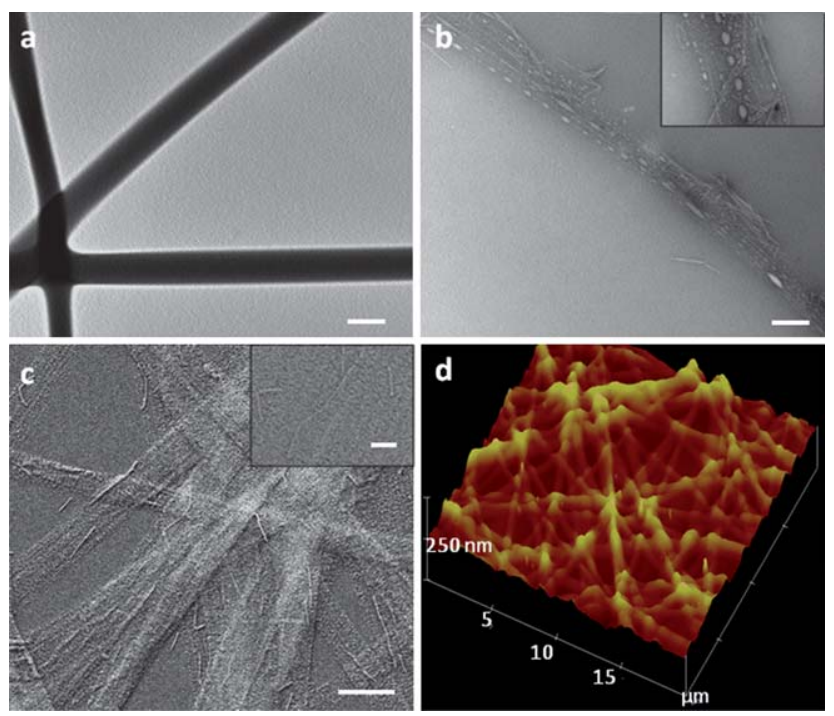

Fig. 4 (a) TEM image of untreated TMV-PVA fibers without negative staining. (b) PVA beads formation of TMV-PVA nanofibers after incubating with uranyl acetate solution ( $2 \%$ in water) for 20 seconds. (c) FESEM image and (d) three-dimensional AFM image show topographic TMV-PVA fibers after sequential treatments with ethanol for $24 \mathrm{~h}$ and with water for 3 days. The inset of (c) is the high resolution FE-SEM indicating the existence of TMV particles. Scale bars are $1 \mu \mathrm{m}$ for (c) and $200 \mathrm{~nm}$ for others. atomic force microscopy (AFM) as seen in Fig. 4. When untreated TMV-PVA nanofibers were incubated with water for 5 min, PVA readily dissolved in water formed bead-like structures, leaving TMV virus in situ as observed in Fig. 4b. With sequential treatments of $24 \mathrm{~h}$ in ethanol and 3 days in water, the treated TMV-PVA mat was characterized by a high resolution FESEM (Fig. 4c). It is found that some short rod-like structures are aligned on fibers. Under high magnification shown in the inset of Fig. 4c, the rod has been identified to be TMV particles based upon the length and physical appearance. Most of TMV particles are aligned along the electrospun fibers. Therefore, after a series of treatments, the water stability of TMV-PVA nanofibers has been improved and the fiber can stay in water for 3 days due to the partial crystallization of PVA. Fig. $4 d$ displays the thickness of the sequential treated nanofiber mat measured by a 3D AFM imaging. A nonwoven fibrous network with a height of around $500 \mathrm{~nm}$ is observed. This indicated that after a three-day soak in water, the majority of TMV-PVA fibers remained on the mat.

\subsection{Mechanical characterization of the individual TMV-PVA nanofiber}

The mechanical properties of the fibrous scaffold are critical to the further tissue engineering application. Without adequate mechanical support from the scaffold, any nascent tissue formation may fail due to excess deformation. ${ }^{37}$ The mechanical characterization of Young's modulus of the as-spun individual nanofiber of the fibrous scaffold was therefore conducted using our homemade nanomanipulator. ${ }^{38}$ This nanomanipulator consists of two independent operating stages $(x, y)$ and $(z, \theta)$. Each operating stage is capable of nanometre resolution linear motion and single axis $360^{\circ}$ rotational motion. Two AFM cantilever probes (with a spring constant $(k)$ of $0.73 \mathrm{~N} \mathrm{~m}^{-1}$ for a short cantilever and $0.1 \mathrm{~N} \mathrm{~m}^{-1}$ for a long cantilever) were mounted onto one stage, and a tungsten tip was mounted on the other stage. In a typical experiment, a nanofiber was firstly picked up by a tungsten tip from the edge of a nonwoven nanofiber mat (Fig. 5a) and buckled by localized electron-beaminduced deposition (EBID) ${ }^{38}$ of docosane (Aldrich) inside the SEM. The other end of the fiber was mounted onto a short cantilever probe and tethered by EBID as well. The long cantilever was employed as a reference to measure the deflection of the short cantilever during the tensile test. When both ends of a nanofiber were mounted, careful adjustment of the two stages was taken to make sure that the nanofiber was in the focus plane of the SEM and normal to both the tungsten tip and the AFM tip.

In a typical tensile test, we moved the tungsten tip perpendicularly to pull the nanofiber so that the nanofiber was stretched and the AFM cantilever was deflected (Fig. 5c-f). The strain $(\varepsilon)$ was obtained by measuring the relative change of the length of the nanofiber in a series of SEM images, e.g. $\varepsilon=\Delta L / L_{0}$. The Young's modulus $(E)$ of the nanofibers can be extracted from the slope of the stress-strain curve in which Hooke's law holds, $E=$ $\sigma_{\mathrm{E}} / \varepsilon$. The applied loading force was obtained by measuring the deflection of the short AFM cantilever, so that the stress $\sigma_{\mathrm{E}}$ can be calculated by eqn (1): 

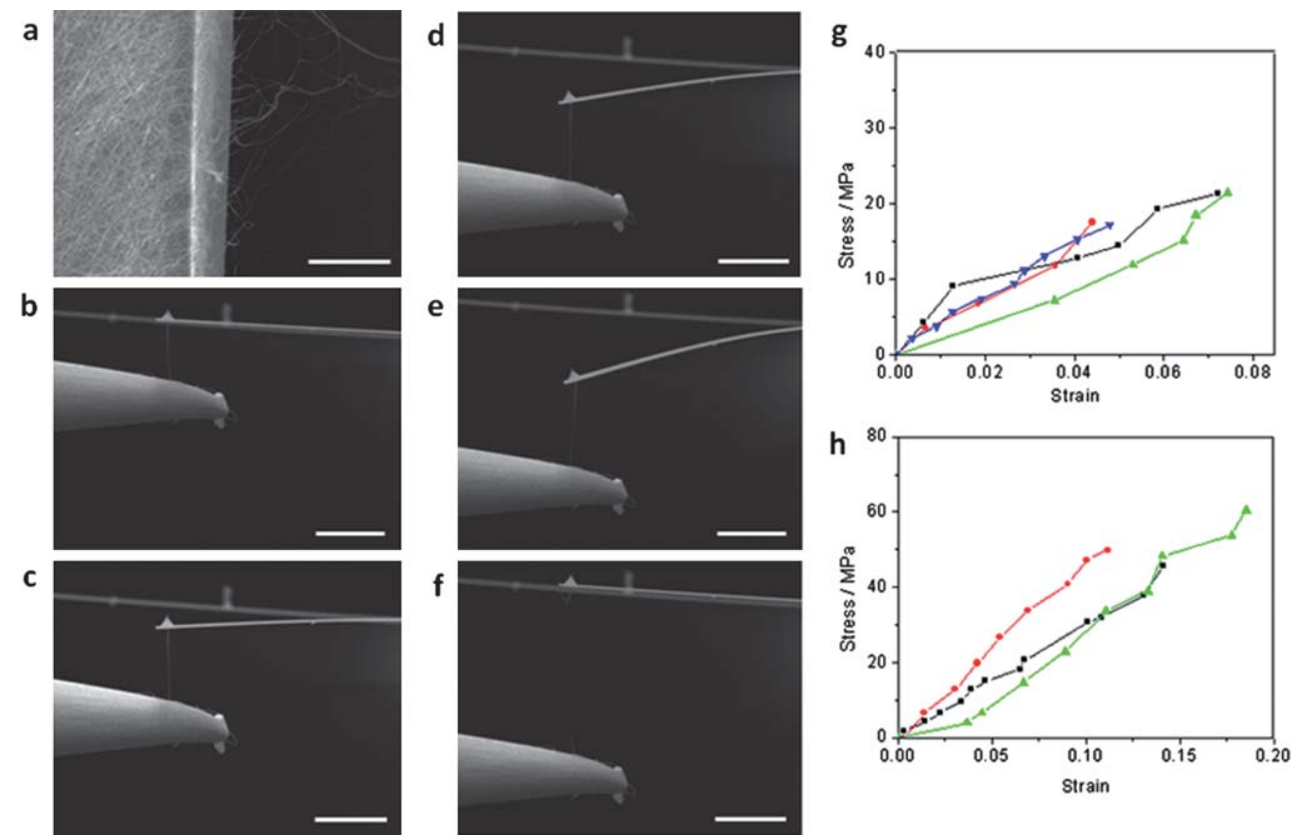

Fig. 5 Tensile testing of individual TMV-PVA electrospun composite nanofibers and PVA nanofibers using a homemade nanomanipulator. (a) SEM images of nanofibers protruding out of the edge of the nonwoven fibrous mat. (b-f) SEM images of the deflection of an AFM cantilever (the spring constant $(k) 0.73 \mathrm{~N} \mathrm{~m}^{-1}$ ) with the fiber stretched perpendicularly. (g) Stress-strain curves of TMV-PVA fibers. (h) Stress-strain curves of PVA nanofibers. The slope of the curve represents Young's modulus $(E)$ which is $315 \pm 51.4 \mathrm{MPa}$ for TMV-PVA nanofibers and $342.47 \pm 106.84 \mathrm{MPa}$ for PVA nanofibers (the values were obtained based on the average of three to four tests). Scale bars are $20 \mu \mathrm{m}$.

$$
\sigma_{E}=\frac{F}{A_{0}}=\frac{k \times \Delta \delta}{\pi\left(\frac{d}{2}\right)^{2}}
$$

where $\sigma_{\mathrm{E}}$ represents the tensile stress, $\Delta \delta$ is the deflection of cantilever, and $d$ is the original diameter of a tested nanofiber. If the mounted nanofiber was deviated from the AFM tip, the spring constant of the cantilever, $k$, could be calibrated following the eqn (2): ${ }^{39}$

$$
k_{A}=\frac{2 L_{C}^{3}}{L_{A}^{2}\left(3 L_{A}-L_{C}\right)} k_{C}
$$

In the equation, $k_{\mathrm{A}}$ is a spring constant of the silicon cantilever at tip, $k_{\mathrm{C}}$ is a spring constant at the position where the fiber actually mounted, $L_{\mathrm{A}}$ is the length of AFM tip to the cantilever support, and $L_{C}$ is the length of fiber loading site to the cantilever support.

After the calibration, both TMV-PVA and PVA nanofibers were examined by the nanotensile testing. The corresponding stress-strain curves were plotted in Fig. $5 \mathrm{~g}$ and h. The Young's modulus of TMV-PVA fiber was calculated to be $315.0 \pm$ 51.4 $\mathrm{MPa}$ which was slightly lower than that of the PVA fiber $(342.5 \pm 106.8 \mathrm{MPa})$. Therefore, the introduction of TMV virus hardly impaired the mechanical properties of the electrospun nanofiber, while promoting biocompatibility and the potential application in tissue engineering, drug loading and release systems.

\subsection{Coelectrospun nanofibers of PVA with chemically functionalized TMV}

Since surface modification of TMV could be readily achieved via genetic or chemical methods, this co-electrospinning process offers a facile way to incorporate a variety of functionalities into

polymer nanofibers. As shown in Fig. 6a, a fluorescent anthracene motif could be covalently conjugated to the glutamatic residues 97 and 106 in the interior surface of TMV using a sequential amidation reaction followed by $\mathrm{Cu}(\mathrm{I})$ catalyzed alkyne-azide cycloaddition (CuAAC) reaction. ${ }^{40,41}$ The attachment of dye to TMV was monitored by UV-vis (Fig. 6b), fluorescence spectrometry (Fig. 6c), and MALDI-TOF MS (Fig. 6d). The anthracene derivatized TMV (TMV-An) could be cospun with PVA using the same aforementioned protocol. Both optical and confocal microscopy images showed that TMV-An particles were homogeneously distributed in fibers (Fig. 6e and f).

\subsection{Cell spreading on TMV-PVA mats with TMV mutant}

To demonstrate the versatility of the co-electrospinning method in incorporating functional TMV particles, a mutant TMV displayed with RGD sequences was generated and used in our study (see details in the Materials and methods, Section 2.3). The insertion of GRGDSPG peptide was confirmed by MALDITOF MS (Fig. 7a) and by sequencing the TMV coat protein gene. It is well known that the RGD sequence, a ligand that can bind to cell surface integrin proteins, can effectively promote the cell adhesion. ${ }^{42}$ In our study, the baby hamster kidney (BHK) cell was used due to its great adhesion response to RGD motifs. Additionally, unlike most of other cells, the BHK cell has limited ability to secrete its own extracellular matrix proteins; therefore it will offer a much direct response to surface chemistries. ${ }^{43}$

The coelectrospun TMV-RGD-PVA nanofibers were fabricated successfully using the same condition as described in Materials and methods, Section 2.1, and tested in BHK cells culturing. Then each well was seeded $5 \times 10^{4} \mathrm{BHK}$ cells in serum 

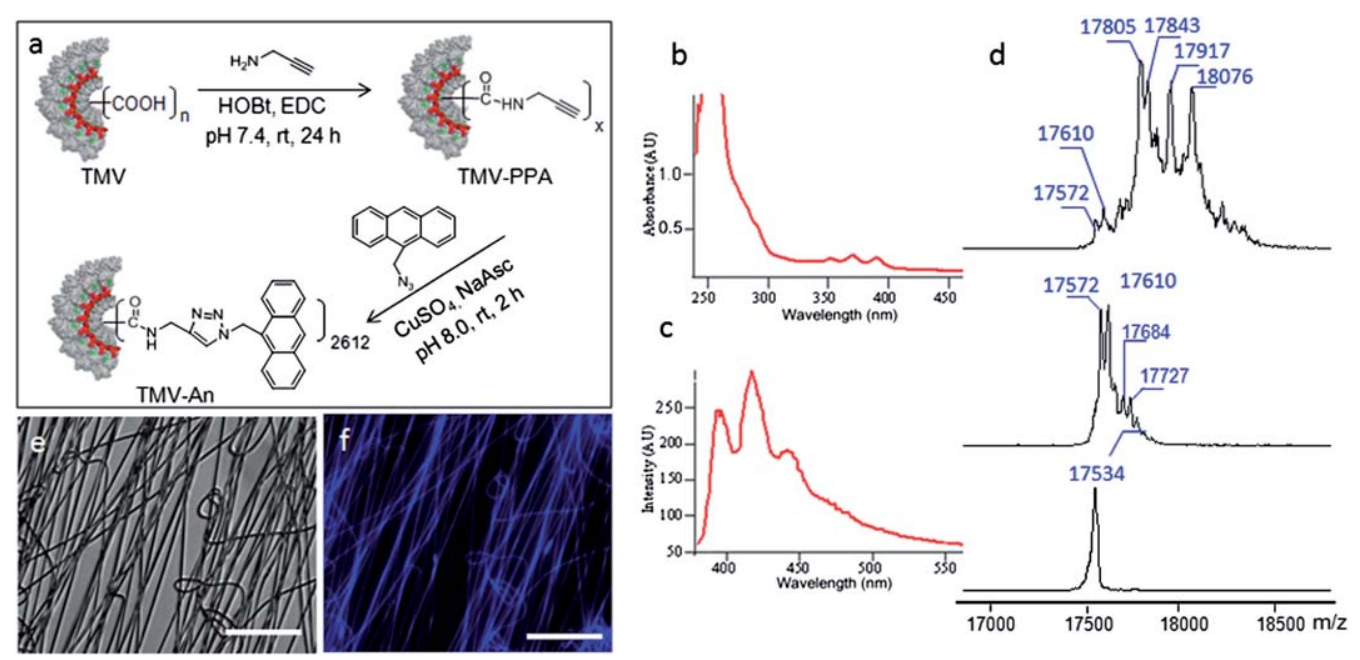

Fig. 6 Coelectrospun conjugated TMV with PVA. (a) Bioconjugation of TMV with anthracene dye using direct amidation reaction followed by a CuAAC reaction. The loading of anthracene units per particle was calculated using the molar extinction coefficient of anthracene: $9700 \mathrm{M}^{-1} \mathrm{~cm}^{-1}$ at $356.25 \mathrm{~nm}$. (b) UV-vis spectrum of wt-TMV and TMV-An (indicated with arrows). (c) Fluorescence spectrum of TMV-An. (d) MALDI-TOF MS spectra of the subunit protein of wild type TMV $(17534 \mathrm{~m} / \mathrm{z}$ ), PPA modified TMV (17 572 and $17610 \mathrm{~m} / z$; peaks at 17684 and $17727 \mathrm{~m} / z$ belong to TMV coat protein with a side product from the EDC coupling, see ESI $\dagger$ ), and the CuAAC reaction products (17 572 and $17610 \mathrm{~m} / \mathrm{z}$; peaks at 17684 and $17727 \mathrm{~m} / \mathrm{z}$ belong to the TMV coat protein with a side product from the EDC adduct, see ESI $\dagger$ ), and CuAAC reaction products (17 805, 17843,17960 , and $18076 \mathrm{~m} / \mathrm{z}$; for detailed explanation see ESI $\dagger$ ). (e) Optical and (f) fluorescent images of coelectrospun TMV-PVA-An; scale bars are $50 \mu \mathrm{m}$.

free media. Since serum contains many complex growth factors and adhesive proteins, the absence of serum will be necessary to investigate the direct interactions between the virus materials and cells. After $1 \mathrm{~h}$ of cell seeding, cells on PVA and TMV-PVA were observed to have round shape morphology and tend to cluster together. ${ }^{44}$ As a comparison, most cells cultured on TMV-PVARGD nanofibrous mats were well attached and had formed prominent actin filaments (Fig. 7i). The cell density on each fibrous substrate was determined by averaging (how many fields of view in how many experiments) (Fig. 7b). Based on these results, the incorporation of TMV-RGD into PVA fibers had efficiently enhanced cell adhesion. Because of the absence of the essential nutrient in the serum free medium, cells gradually died and peeled off from PVA and TMV-PVA; therefore, decreased cell densities were observed after $12 \mathrm{~h}$ incubation. Cells grown on PVA and TMV-PVA fibrous substrates showed randomized
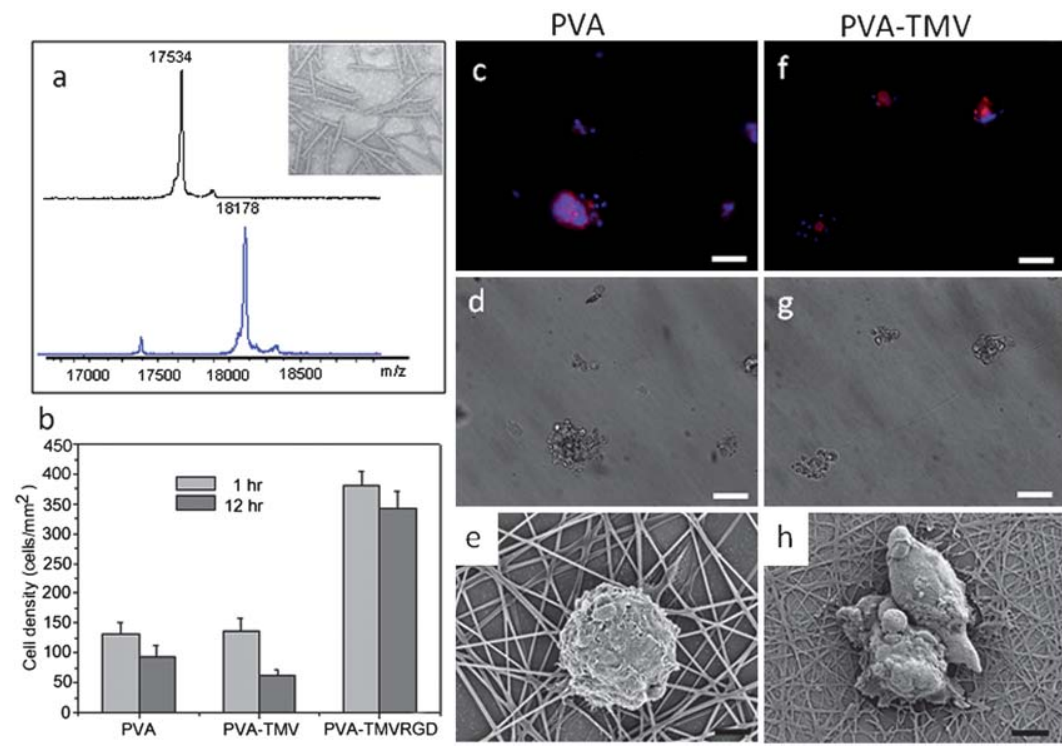

PVA-TMV-RGD1
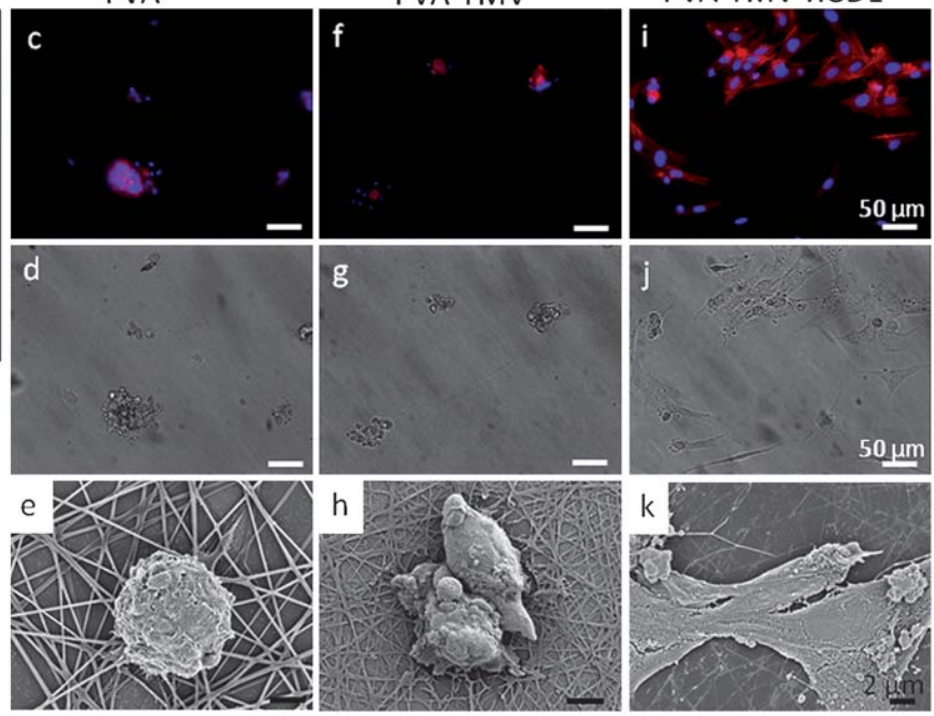

Fig. 7 (a) MALDI-TOF spectrum of mutant TMV-RGD $(18178 \mathrm{~m} / \mathrm{z})$ and wt-TMV $(17534 \mathrm{~m} / \mathrm{z})$, the inset is a TEM image of mutant TMV. (b) Cell density analyses after cell incubated for $1 \mathrm{~h}$ and $12 \mathrm{~h}$ on PVA, TMV-PVA and TMV-PVA-RGD fibers. (c, $\mathrm{f}$, and i) Fluorescence microscopy images and ( $d$, g, and j) optical images of cells incubated on PVA, TMV-PVA, and TMV-PVA-RGD nanofibers, respectively. Nuclei were stained with DAPI (blue) and the F-actin was stained with rhodamine-phalloidin (red). (e, h, and k) FESEM image of cells on electrospun PVA, TMV-PVA, and TMVPVA-RGD nanofibers, respectively. 
actin (red) structure (Fig. 7c and f). In comparison, BHK cells spread nicely on TMV-PVA-RGD nanofibers with prominent F-actin stress fibers (Fig. 7i). Under an optical microscope or field emission scanning electron microscope (FESEM), cells showed weak interactions with fibers when seeded on PVA and TMV-PVA, remaining the round shape structure in the absence of serum media (Fig. 7e and h). Different from that TMV-PVARGD cells were found to well spread over the fibrous mat (Fig. 7j and $\mathrm{k}$ ). The average cell area was much larger than that on PVA or TMV-PVA fibers. Evidently, TMV can serve as a carrier to introduce bioactive peptides (in this case it was RGD peptide) to modulate cellular response.

\section{Conclusions}

In summary, TMV-PVA nanofibers were successfully fabricated with a diameter ranging $300-400 \mathrm{~nm}$ using the electrospinning technique. In various TMV concentrations, the hybrid TMVPVA electrospun nanofibers were smooth without drops and homogeneously distributed on a grounded collector, indicating no difference with the as-spun PVA fibers. Under high magnification TEM and SEM images, TMV particles were well aligned along the electrospun fiber at low TMV concentrations while displaying a certain level of random distribution at high TMV concentrations due to protein-protein interactions. To enhance the water resistance of TMV-PVA fibers, ethanol treatment was employed to increase the partial crystallization of PVA and therefore increased the stability of fibers in water. In addition, the mechanical properties of individual PVA nanofibers and TMVPVA hybrid nanofibers were measured in situ in SEM using a homemade nanomanipulator, which, in general, is more accurate in comparing with the reported methods of three-point bending ${ }^{45}$ and nanotensile tester. ${ }^{46,47}$ The Young's modulus of the TMV-PVA nanofibers was measured to be $315.0 \pm$ $51.4 \mathrm{MPa}$, which is comparable with that of the as-spun PVA nanofiber (300-400 $\mathrm{nm}$ in diameter). The result indicates that the hybridization of TMV into PVA did not impair the mechanical properties of the electrospun fibers. Therefore this method can be used in the fabrication of a broad range of composite nanofibers using synthetic polymers and bionanoparticles as starting materials. Since TMV as a building block can be tailored with various functional groups by both chemical conjugation and mutagenesis, the coelectrospun process can incorporate a variety of functionalities into PVA fibers. We demonstrated that the mutant TMV-RGD can be co-spun with PVA into nanofibers, which could be used as substrates for cell adhesion studies. Our results demonstrate the great potential of this method in fabricating bioactive fibrillar materials.

\section{Acknowledgements}

This work was partially supported by the National Science Foundation (CHE-0748690 and DMR-0706431), the Alfred P. Sloan Scholarship, the Camille Dreyfus Teacher Scholar Award, DoD-W911NF-09-1-0236, and the W. M. Keck Foundation. XL would like to acknowledge the financial support from the National Science Foundation (CMMI-0653651 and CMMI0824728).

\section{References}

1 C. P. Barnes, S. A. Sell, E. D. Boland, D. G. Simpson and G. L. Bowlin, Adv. Drug Delivery Rev., 2007, 59, 1413-1433.

2 J. S. Choi, S. J. Lee, G. J. Christ, A. Atala and J. J. Yoo, Biomaterials, 2008, 29, 2899-2906.

3 W. Wang, S. Itoh, K. Konno, T. Kikkawa, S. Ichinose, K. Sakai, T. Ohkuma and K. Watabe, J. Biomed. Mater. Res., Part A, 2009, 91, 994-1005.

4 B. M. Baker and R. L. Mauck, Biomaterials, 2007, 28, 1967-1977.

5 V. Vogel and G. Baneyx, Annu. Rev. Biomed. Eng., 2003, 5, 441-463.

6 S. H. Hyon, W. I. Cha, Y. Ikada, M. Kita, Y. Ogura and Y. Honda, J. Biomater. Sci., Polym. Ed., 1994, 5, 397-406.

7 A. V. Reis, A. R. Fajardo, I. T. A. Schuquel, M. R. Guilherme, G. J. Vidotti, A. F. Rubira and E. C. Muniz, J. Org. Chem., 2009, 74, 3750-3757.

8 J. Zeng, A. Aigner, F. Czubayko, T. Kissel, J. H. Wendorff and A. Greiner, Biomacromolecules, 2005, 6, 1484-1488.

9 A. C. Patel, S. X. Li, J. M. Yuan and Y. Wei, Nano Lett., 2006, 6, 1042-1046.

10 S. H. Lim and H. Q. Mao, Adv. Drug Delivery Rev., 2009, 61, 1084 1096.

11 Y. Lin, A. Boker, J. B. He, K. Sill, H. Q. Xiang, C. Abetz, X. F. Li, J. Wang, T. Emrick, S. Long, Q. Wang, A. Balazs and T. P. Russell, Nature, 2005, 434, 55-59.

12 C. E. Flynn, S. W. Lee, B. R. Peelle and A. M. Belcher, Acta Mater., 2003, 51, 5867-5880.

13 (a) M. Young, D. Willits, M. Uchida and T. Douglas, Annu. Rev. Phytopathol., 2008, 46, 361-384; (b) L. A. Lee, Z. Niu and Q. Wang, Nano Res., 2009, 2, 349-364.

14 Y. Huang, C. Y. Chiang, S. K. Lee, Y. Gao, E. L. Hu, J. De Yoreo and A. M. Belcher, Nano Lett., 2005, 5, 1429-1434.

$15 \mathrm{M}$. Comellas-Aragones, H. Engelkamp, V. I. Claessen, N. A. J. M. Sommerdijk, A. E. Rowan, P. C. M. Christianen, J. C. Maan, B. J. M. Verduin, J. J. L. M. Cornelissen and R. J. M. Nolte, Nat. Nanotechnol., 2007, 2, 635-639.

16 J. D. Ramsey, H. N. Vu and D. W. Pack, J. Controlled Release, 2010, 144, 39-45.

17 N. Carette, H. Engelkamp, E. Akpa, S. J. Pierre, N. R. Cameron, P. C. M. Christianen, J. C. Maan, J. C. Thies, R. Weberskirch, A. E. Rowan, R. J. M. Nolte, T. Michon and J. C. M. Van Hest, Nat. Nanotechnol., 2007, 2, 226-229.

18 Y. J. Lee, H. Yi, W. J. Kim, K. Kang, D. S. Yun, M. S. Strano, G. Ceder and A. M. Belcher, Science, 2009, 324, 1051-1055.

19 G. Kaur, C. Wang, J. Sun and Q. Wang, Biomaterials, 2010, 31, 58135824.

20 G. Kaur, M. T. Valarmathi, J. D. Potts, E. Jabbari, T. Sabo-Attwood and Q. Wang, Biomaterials, 2010, 31, 1732-1741.

21 J. Rong, L. A. Lee, K. Li, B. Harp, C. M. Mello, Z. Niu and Q. Wang, Chem. Commun., 2008, 5185-5187.

22 Y. Lin, E. Balizan, L. A. Lee, Z. W. Niu and Q. Wang, Angew. Chem., Int. Ed., 2010, 49, 868-872.

23 G. Kaur, M. T. Valarmathi, J. D. Potts and Q. Wang, Biomaterials, 2008, 29, 4074-4081.

24 (a) Z. W. Niu, M. A. Bruckman, B. Harp, C. M. Mello and Q. Wang, Nano Res., 2008, 1, 235-241; (b) Z. Niu, J. Liu, L. A. Lee, M. A. Bruckman, D. Zhao, G. Koley and Q. Wang, Nano Lett., 2007, 7, 3729-3733; (c) Z. Niu, V. S. Kotakadi, J. He, T. Emrick, T. P. Russell, L. Yang and Q. Wang, Chem. Commun., 2006, 30193021; (d) Z. Niu, M. Bruckman, S. Li, L. A. Lee, B. Lee, S. V. Pingali, P. Thiyagarajan and Q. Wang, Langmuir, 2007, 23, 6719-6724; (e) J. H. Rong, F. Oberbeck, X. N. Wang, X. D. Li, J. Oxsher, Z. W. Niu and Q. Wang, J. Mater. Chem., 2009, 19, 2841-2845.

25 (a) T. Li, B. Ye, Z. W. Niu, P. Thompson, S. Seifert, B. Lee and Q. Wang, Chem. Mater., 2009, 21, 1046-1050; (b) T. Li, L. Y. Wu, N. Suthiwangcharoen, M. A. Bruckman, D. Cash, J. S. Hudson, S. Ghoshroy and Q. Wang, Chem. Commun., 2009, 2869-2871; (c) T. Li, Z. W. Niu, T. Emrick, T. R. Russell and Q. Wang, Small, 2008, 4, 1624-1629; (d) Z. Su and Q. Wang, Angew. Chem., Int. Ed., 2010, 49, 10048-10050; (e) T. Li, Z. W. Niu, N. Suthiwangcharoen, R. Li, P. E. Prevelige and Q. Wang, Sci. China Chem., 2010, 53, 71-77.

26 P. G. Holder, D. T. Finley, N. Stephanopoulos, R. Walton, D. S. Clark and M. B. Francis, Langmuir, 2010, 26, 17383-17388. 
27 M. Comellas-Aragones, A. de la Escosura, A. J. Dirks, A. van der Ham, A. Fuste-Cune, J. J. L. M. Cornelissen and R. J. M. Nolte, Biomacromolecules, 2009, 10, 3141-3147.

28 C. Y. Chiang, C. M. Mello, J. J. Gu, E. Silva, K. J. Van Vliet and A. M. Belcher, Adv. Mater., 2007, 19, 826-832.

29 S. W. Lee and A. M. Belcher, Nano Lett., 2004, 4, 387-390.

30 W. Salalha, J. Kuhn, Y. Dror and E. Zussman, Nanotechnology, 2006, 17, 4675-4681.

31 E. P. S. Tan and C. T. Lim, Rev. Sci. Instrum., 2004, 75, 2581-2585.

32 R. Higuchi, B. Krummel and R. K. Saiki, Nucleic Acids Res., 1988, 16, 7351-7367.

33 C. A. Holt and R. N. Beachy, Virology, 1991, 181, 109-117.

34 L. Yao, T. W. Haas, A. Guiseppi-Elie, G. L. Bowlin, D. G. Simpson and G. E. Wnek, Chem. Mater., 2003, 15, 1860-1864.

35 E. R. Kenawy, F. I. Abdel-Hay, M. H. El-Newehy and G. E. Wnek, Mater. Sci. Eng., A, 2007, 459, 390-396.

36 C. M. Hassan and N. A. Peppas, Macromolecules, 2000, 33, 24722479.

37 S. J. Hollister, Nat. Mater., 2005, 4, 518-524.
38 C. H. Lin, H. Ni, X. N. Wang, M. Chang, Y. J. Chao, J. R. Deka and X. D. Li, Small, 2010, 6, 927-931.

39 Z. H. Xu, M. A. Sutton and X. D. Li, Acta Mater., 2008, 56, 6304 6309.

40 T. L. Schlick, Z. B. Ding, E. W. Kovacs and M. B. Francis, J. Am. Chem. Soc., 2005, 127, 3718-3723.

41 M. Bruckman, G. Kaur, L. A. Lee, F. Xie, J. Sepulveda, R. Breitenkamp, X. Zhang, M. Joralemon, T. P. Russell, T. Emrick and Q. Wang, ChemBioChem, 2008, 9, 519-523.

42 E. Ruoslahti and M. D. Pierschbacher, Science, 1987, 238, 491497.

43 B. Stevens, Trans. Faraday Soc., 1967, 63, 1305.

44 F. Grinnell and M. K. Feld, Cell, 1979, 17, 117-129.

45 J. F. Graveland-Bikker, I. A. T. Schaap, C. F. Schmidt and C. G. de Kruif, Nano Lett., 2006, 6, 616-621.

46 C. T. Lim, E. P. S. Tan and S. Y. Ng, Appl. Phys. Lett., 2008, 92, 141908 (141903p).

47 E. P. S. Tan, S. Y. Ng and C. T. Lim, Biomaterials, 2005, 26, $1453-$ 1456. 